\title{
Research on the Teaching Mode Reform of Creation Sculpture Course in Universities
}

\author{
Xiaofei Lu \\ School of Arts, Xi'an University of Science and Technology, \\ Xi'an, Shaanxi Province, 710054 \\ e-mail: 23700634@qq.com
}

Abstract-Research on the teaching mode reform of creation sculpture course in Universities takes the innovating education as the basis to discuss how to adapt to the requirements of economic and social developments. This paper also researches the teaching mode system to cultivate high-quality creative and well-designed talents of art. Simply say, this is to think to provide what kids of the sculpture creative and well-designed talents for the society. Meanwhile, it is aimed to inherit tradition, base on the present, look up to the future, innovate, open and forge ahead, so as to cultivate high-level sculpture creative and well-designed talents. Then, this research can make the education of sculpture creation expanded into an education with innovation, synthesis, pluralism, ample and stereoscopic. Breaking the original single and separate education teaching mode, this research created the construction from the modeling techniques teaching creation on single base into multi-orientation teaching system of sketch modeling design, creative design theoretical teaching, formal language transformation, and discussion combined with practice". Finally, this research achieves the integration of theoretical appreciation, practice and creation on sculpture design, as well as the establishment of old exams, multimedia network application, multi direction practical teaching. Moreover, teaching information is expanded, and the students' perspective is enriched, as well as the system of knowledge is strengthened and a new teaching mode of comprehensive professional skill education is built in sculpture design talents training.
Keywords-Sculpture; Creation; Teaching Mode; Educational Means

\section{INTRODUCTION}

It required us to keep pace with times for the rapid changes and developments in social economic as well as the increase, movement and amalgamation of information technology and new knowledge. On the one hand, the time calls and requires us to be updated and creative, when facing the complexity of the students' knowledge structure. On the other hand, this research is necessary for us to construct a reasonable teaching syllabus pioneering and innovative teaching methods, which is aimed to improve the quality of teaching. As a universities art educator, it is not enough to only teach basic skills of the art education in modern universities. Continuously innovate and explore new teaching ideas and methods is the topic that every teacher must do for his whole life is a research.

\section{THE IMPORTANCE AND CURRENT SITUATION OF}

\section{SCULPTURE CREATION COURSE IN UNIVERSITIES}

With the establishment of art design disciplines in various universities and the related professions, it has been expanded whether in the professional enrollment or in the number of classes. The number of the students in each class is from several people and a dozen people in the past to twenty or thirty people in a class today. Meanwhile, the number of classes is from one or two in the past to four or five classes at present. However, the overall foundation of basic ability for students to modeling is so weak, and there is only the intensive training for targeted examination in several months before 
entering the school. They got the admissions only relying on the training of silent sketch characters and color still life. Therefore, when the sculpture creation course is popularized to higher education in the country, the weakness of students' basic professional ability, feeling ability and modeling ability caused great difficulty in carrying out the teaching. So the professional teachers should spend a lot of time and energy to make up the missed lessons, and adjust the teaching plans, so as to smoothly complete a relatively uniform teaching schedule, which becomes the consensus of higher school education in recent years. It is really difficult to carry out the sculpture teaching, and all teachers devoted too much time and efforts to make up a large number of basic links. Therefore, the teaching plan cannot be enhances in further, and it barely can be in a relatively smooth progress. In recent years, the understanding of professional art teachers on the sculpture creation is limited to a single way, and it is anxious to be broken up.

In current art education, the sculpture design is classified into a part of the public environment, landscape, and cultural landscape, so the practical and innovative table of its own unique space in the cultivation of sculpture creation ability is very important, in addition to the skills like training modeling ability and creating and shaping the form of language. The ontology of sculpture art is that it participates and shapes the landscape environment as a kind of construction. Meanwhile, the inspiration of sculpture is its modeling language and space idea. All of these are the importance of sculpture course for students to understand the space of understanding. Through learning, it can help students from the instinctive observation of two-dimensional space into rational observation, analysis of three-dimensional space and multidimensional space. Based on this, the thoughts of cultivating sculpture creation and well-designed talents for the society, are mainly on how to avoid weaknesses and short board, rather than relying on other previous basic ability of the students. Instead, it is required to explore, inspire, guide, and keep pace with the times. Furthermore, looking for the best teaching method of education is imminent, as well.

\section{INNOVATE AND REFORM THE EDUCATION TEACHING}

\section{MODE OF SCULPTURE CREATION COURSE IN UNIVERSITIES}

The exploration on the reform and innovation of creation sculpture course in universities is based on the new situation and new requirements of the development of social economy and culture. The reform of double first-class teaching creation sculpture course in universities should be vigorously promoted, so as to adapt to the requirements of the public aesthetic consciousness under the material prosperity and the city public culture. In the past, the problems of the single teaching model have risen one after another, but now it has been broken. The aesthetic concept of modern people puts forward a new challenge to the traditional language of sculpture, and it becomes more and more difficult to be satisfied in the aesthetic. In the face of the social demand of new creation and artistic talents, education teaching modes from domestic and foreign outstanding universities should be referred to solve the above problems. Meanwhile, based on the results from years of teaching experience, the research on the innovative reform teaching modes should be started on the theoretical research, aimed to improve the educating concept of operational skills.

Although the basic professional skills of most students was poor before their entries, the young students are activity, quick thinking, active thinking, and easy to accept new things, with various accesses to search information, which is their advantages and strengths. Teaching students in accordance with their aptitude, it is not only relies on their foundations in the improvement of professional quality and the advancement of professional skills. If the teaching method is efficient, new methods and new teaching mode good at inspiring, guiding and exploring is the guarantee to help most of the students to achieve rapid and long-term progress. The key is to make the exploration and researches on education and teaching keep pace with the times and find the best and most reasonable education and targeted teaching methods.

The sculpture creation course pays attention to the performance of skills, which needs a certain amount of class hours to get the system rigorous teaching sequence process, so 
as to achieve the good educational effects. However, due to the professional settings and the limitations of the teaching software and hardware, the contemporary sculpture courses will no longer take a lot of time to enhance students' basic modeling ability, creative techniques and operating skills, according to discipline construction and configuration of sculpture teaching. By seizing the advantages of activity and various ways to get information and so on, improve students' professional qualities in the use of appropriate education. Meanwhile, the rich theoretical knowledge should be constructed, and the theoretical knowledge should be excluded while teaching. In the teaching outlines, the methods like historical introduction, picture comparison, and excellent works appreciation should be set. All of these are aimed to help the students understand the creation of sculpture, and get the first time to arouse their interests in learning this course.

In the study of solid theoretical knowledge, the practical training is carried out, which is do what in old exams. In the progress from sculpture design to sculpture molding, flexible application of education should be adopted and it emphasizes the macro grasp, not restricted in a certain level section. However, the specific production techniques of sculpture and production process should not be underestimated. Meanwhile, the teaching link do what in old exams begins at a rigorous sculpture design sketch. In the final production process, it takes the proper application techniques as the main line, and then establishes the three-dimensional, four-dimensional and other multidimensional sculpture creation, so as to cultivate students' innovation. The progress may be changeable, and the teaching may be changeable, as well. According to the students' professional ability and understanding, the correct observation method, formal language and technical performance are emphasized. The first is creation practice, then it is teaching theory, and the last is teaching methods for practice. Besides, the practice teaching mode may be difficult afterwards or easy afterwards. Meanwhile, if there are problems in the effects, students can learn with questions, and subtly enhance their learning initiative, so as to change the passive acceptance of knowledge to actively learn and explore the knowledge, as well as avoiding the single preconceptions in teaching course. Generally speaking, this kind of reform promotes the students' enthusiasm to learn and creative design consciousness, as well as arousing their desire to deeply understand the sculpture creation course.

Doing what in the old exams is teaching method guided by theories. The teaching mode of practice takes design and creation as a key. Both of them reflect that the creation sculpture course in universities is course to cultivate innovative ability in three dimensional spaces. In class, the process is "hands on--theory-- after training" which is proved that the teaching method is feasible and scientific by the practices. To some extent, the easy afterwards teaching mode can achieve good results, which is aimed that let the students explore the theories when they encounter problems. Furthermore, it greatly enhances the students' learning initiative and passive acceptance into active exploration and the understanding. Meanwhile, the focus here is to stimulate interest and cultivate students practical skills, such as: the perception of real materials, encouraging students to use the hand-side materials to do some decorative and interesting sculptures, letting the students find the real feelings of sculpture, fully mobilizing the enthusiasm and the innovation consciousness of creative design, and producing infinite desire for the in-depth study of the sculpture design. The teaching mode-- doing what in the old exams is an efficient teaching mode in the sculpture creation science curriculum. This practical teaching mode stresses to follow the real of the sculpture creation theme of the site environment, cultural atmosphere, and audience. At the same time, the students should point at a series of real targets to collect materials, select themes, clear forms, apply materials, and choose implementation processes. In this way, each link of the sculpture course stimulates students' exploration and creative desires. Whatever the outcome is, the whole process is very important to each student, for the reason that they will learn to take the initiative in the creation and take self evaluation, find and solve problems in rational use of the knowledge, as well as finding suitable sculpture design methods. Furthermore, it will cultivate their earnest, rigorous 
and responsible attitudes, so as to enhance the creative design ideas in the social responsibility.

The specific method is: the teaching of sculpture creation takes the real environment, real culture, real audience as the topic, and then let the student choose the topics. Then ask them to collect materials, select themes, clear purposes, apply materials, and choose implementation processes. Each link of the whole teaching process stimulates students' creative desire. As a result, the students learn to think actively in the creation, and reasonably take the application of theoretical knowledge, as well as evaluating the creations, finding and solving problems, and constructing their own learning methods of their architecture design creation. Gradually, it establishes a rigorous attitude and responsible for social ideas.

The innovation and reform of the teaching mode of creation sculpture course in universities also lies in the variety of teaching methods under the knowledge updating speed, and focuses on the summaries and exchanges. That means the end of class hours, but the courses continue. The teachers' teaching process is included summary and feelings, so that they can be exchanged at anytime and anywhere, as well as promoting teaching experience and showing excellent guidance works. This non-classroom teaching mode also includes extracurricular presentations related topics, speeches, symposium, and competitions for college students, etc. In addition to the continuous exchanges of curriculum contents in schools, the communication with other external social academic fields can be carried out synchronously. It includes free artists, sculptors, occupation design company executives, landscape designers, architects and the public. In addition, with the Internet multimedia electronic teaching methods, the lesson extension can be realized, as well, including the use of micro class technology, Mu class and flip class and other forms of combinations.

A reasonable post evaluation system of the course should be established with unified issues, and the creation of doing what in old exams, which means to take the design and plan while given a real environment, the real cultural atmosphere and the real audience. Meanwhile, the topic is not limited, the same as the expressing contents, and the technical materials. This kind of open project design is to give full play to students' imagination and creativity. It is just a part of the creation, and the other part is the teaching evaluation on the subject of work examining and commenting. It cannot be the things only that the students complete the work and teachers score their works, for the reason that the students will not know that the advantages and disadvantages of their works, as well as the creation of sculpture teaching mode reform is redoubled. Therefore, it is the key to make a concentrated comment on the works. The specific methods here include the students' self evaluation, the mutual comments between students and students, and the teachers' comments. Therefore, it is required the teacher to make fair accurate and vivid comments with inspiration,. Meanwhile, it can also be combined with the actual outstanding sculpture cases to inspire students to understand the teacher's understandings and thinking. Such an effective, reasonable and perfect teaching mode of sculpture creation makes the professional cultivation framework system and the teaching contents more three-dimensional, plump and powerful. Diversified methods teaching makes the sculpture creation education in a virtuous circle, and steps into the developing road of the international academic forefront. Moreover, the rapid updating and supplementing teaching content can fully satisfy and meet the requirements of contemporary society for the cultivation of creative talents in sculpture design.

\section{CONCLUSIONS}

The teaching mode reform of creation sculpture course in universities is aimed to explore the correct, scientific and effective education plan. In addition to adapt to the higher professional education under the new situation, it is also to innovate the creation style of sculpture course, which is immutable, regular, stylized and mechanized. Therefore, students' learning enthusiasm can be enhanced and innovation consciousness can be inspired, as well as the unique aesthetic taste of creation can be arisen. Moreover, it can help to innovate the education ideas and promote the progressiveness 
of course. Totally speaking, teaching methods are induced by a three-dimensional induction, plane induction, subjective conception and non realism subjective conception. The purpose of city sculpture design is changed from plane to three-dimensional, from the concrete to the abstract, and from subjective to objective, so as to train more sculpture design talents urgently needed by the society. Finally, make the university catch up with and surpass similar institutions, as well as keeping with high level of international professional standards.

\section{REFERENCES}

[1] (American) Joyce, B., Weil, M., Calhoun, E., teaching mode [M] Beijing: China Light Industry Press, 2004.

[2] Mingzhe Hu. Color expression [M]. Beijing: People's Art Publishing House, 2005.

[3] Rui Liu. Brief talking about the color language in book binding design [J]. Editor's friend.2012 (2), pp. : 109-111.

[4] (France). Caitlin. Grove. Art intervention space[M]. Guilin: Guangxi Normal University press, 2005. 